interest to observe the effort nature makes provided the patient live long enough to get rid of a puralent effusion. There are two places in which the pus may point. In Case 2 an abscess was opened over the ensiform cartilage, which post mortem was found to be connected by a sinus with the pericardium.

In Case 5 the pus had burrowed forward and would have pointed in the second left interspace close to the sternum. To Professor Rosentein of Leyden is due the credit of being the first to incise and drain the pericardium, the patient recovering completely; the second case, which was also successful, was a patient under the care of Dr. West. Since then the operation has been performed with varying success. Of the 17 cases tabulated 6 are reported to have recovered, but the cases are too few to draw up any reliable statistics. Incision into the pericardium has now been done a sufficient number of times to make it clear that there is no great difficulty or danger about the operation, and I think it must be allowed that it offers the only reasonable hope of recovery to a patient suffering from purulent pericarditis.

Leicester.

\section{A SIMPLE METHOD FOR CONTROLLING HÆMORRHAGE DURING DISARTICU- LATION AT THE HIP.}

BY J. LYNN THOMAS, F.R.C.S. ENG.,

ASSISTANT SURGEON TO THE CARDIFF INFIRMARY; CONBULTING SCRGEOY TO THK CARDIFF PROVIDENT DISPENSARY.

IN emergencies the ideal method for controlling hæmorrhage in amputation at the hip-joint is undoubtedly that which requires no special instruments in one's operation bag. Perhaps the majority of the younger surgeons do not

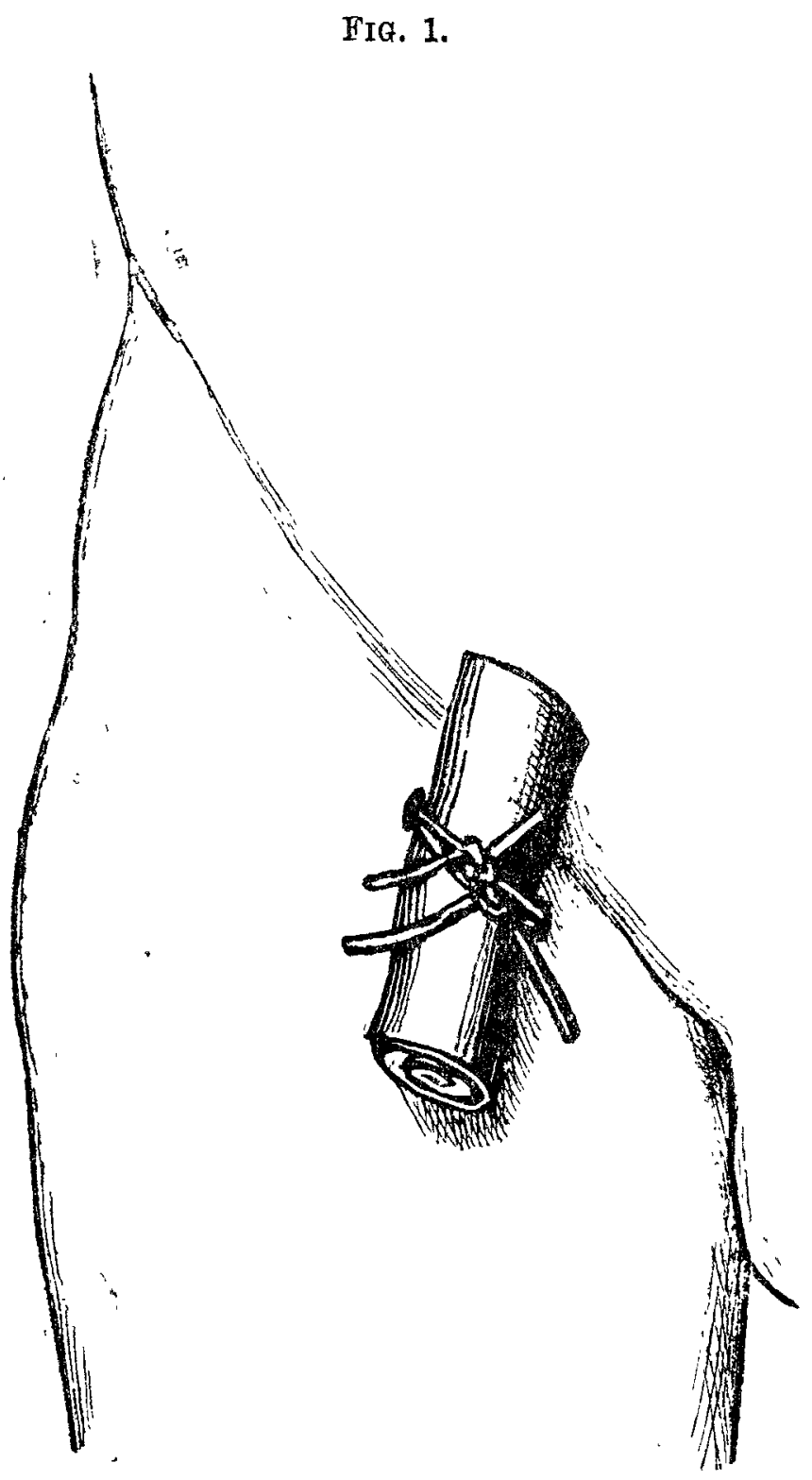

realise that the loss of blood is quite insignificant in dis articalation of the hip by the anterior rachet incision because the femoral artery and vein are ligated at the outset of the operation (Treves). I should think the amount of blood lost is less than the quantity of blood driven into the body by vertical elevation of the limb for a couple of minutes prior to the operation. In a properly equipped operation room surrounded by competent assistants the surgeon can adopt either a simple or a complicated method of arresting the hæmorrhage with equal comfort and confidence of success, but in a badly lighted room with incom. petent or inefficient assistance in a private house ampntation at the hip becomes a very serious and anxious undertaking, unless one happens to possess two one-foot skewers and at least two yards of indiarubber tubing in the operation bag (Wyeth's). In Swain's “Surgical Emergencies" (fifth edition) Davy's lever and Jordan Lloyd's methods are the only two referred to in connexion with the arrest of hæmorrhage in disarticulation of the hip. The first method is practically obsolete, though extremely ingenious, and very few men are au fait with the other method.

During the last twelve months I have had to disarticulate at the hip on three occasions, once at the infirmary and twice in private practice, (1) for sarcoma of the femur, (2) for osteomyelitis of the femur, and (3) for an injury. On one occasion I used with satisfaction the following method. The common

FIG. 2.

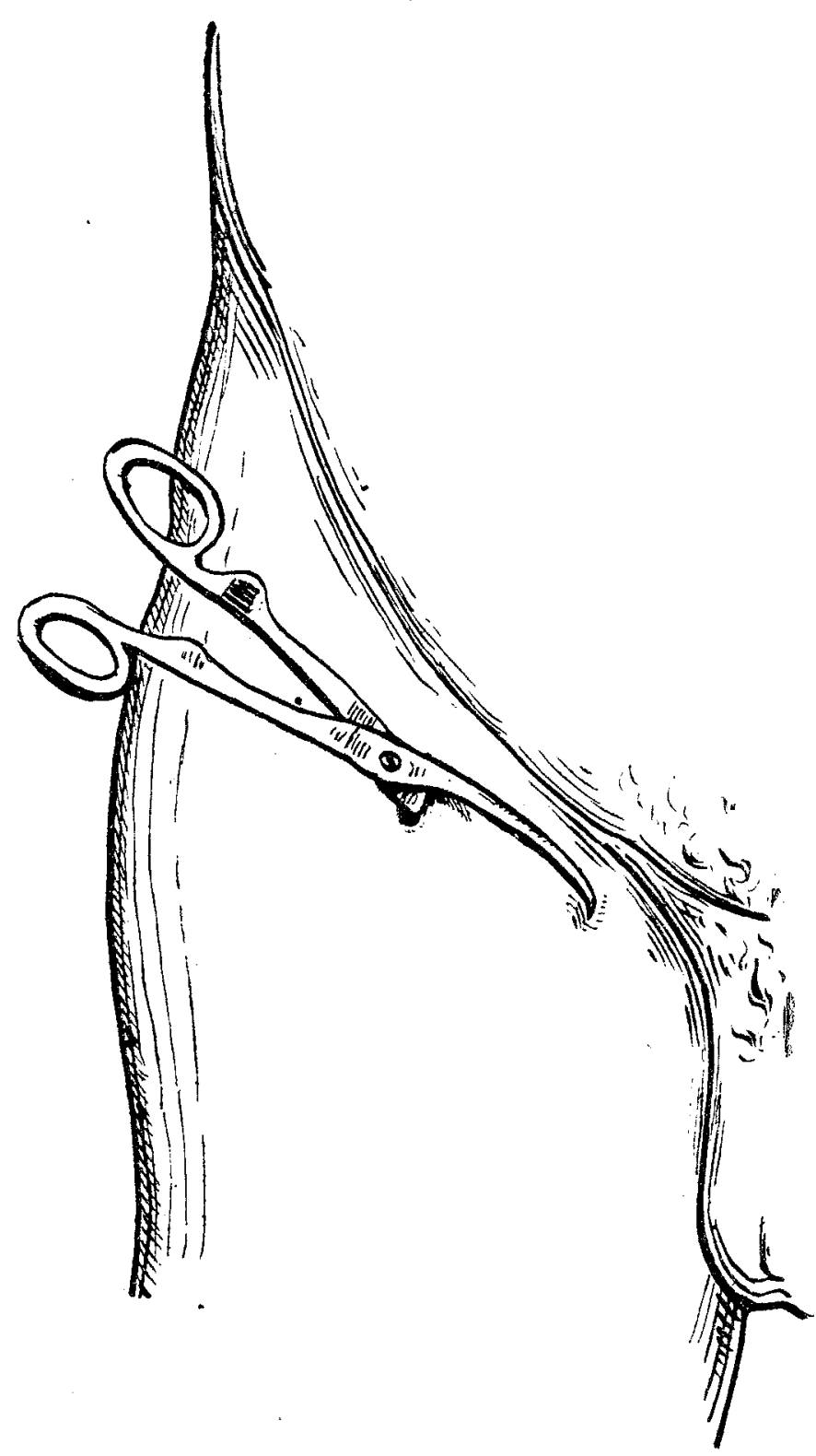

femoral artery and vein were temporarily compressed imme diately below Poupart's ligament. At this point the artery is quite superficial and easily felt and is well above the origin of the deep femoral artery. The femoral pulse being felt I made two stab punctures in the skin, one about an inch outside the pulse and the other about two inches to its inner side-i.e., immediately below the pubic spine. An aneurysm needle with two eyes (Horsley's pattern), which I always carry in my bag, was pushed from one stab-puncture well behind the artery and vein to the other stab-puncture and two long, thick silk ligatures were carried through in withdrawing the needle, then a pad of Gamgee tissue was rolled up and placed over the artery between the punctures and the two silks were tied separately over the Gamgee 
tissue, and thus the vessels were efficiently and satisfactorily occluded during the operation. Fig. 1 conveys at a glance the principle involved in this method. It is advisable to simply tie the first stage only of the surgeon's knot and clamp it with forceps and by this means we can easily re-tie if necessary when letting go after ligating the visible blood-vessels on the face of the stamp. The only condition which might embarrass one in adopting this method of controlling hæmorrhage in amputation at the hip would be the occurrence of an irreducible femoral hernia. Fig. 2 illustrates a method of controlling the same vessels by means of a large Doyen's broad ligament forceps; there is only one puncture made on the outer side of the femoral pulse and one blade is forced through behind the vessels and then the forceps is clamped. This method would be quicker and would take only a few seconds to apply, but it means the acquisition of a special instrument which is not in every operation-bag, whilst the first method requires nothing beyond the essentials of every operation-bag.

I am not aware that the principle of under-running the vessels with silk and tying it over them has been applied to the common femoral vessels before, whilst it is a recognised method of treating cirsoid aneurysm of the scalp. It is hardly necessary to add that after placing the ligatures and pad (in the method I once adopted successfully) it is mecessary to elevate the limb to drain it of its blood before tying the knot tightly. If one were amputating at the shoulder-joint single-handed the same method would be found very useful.

$\mathrm{My}$ best thanks are due to my friend Mr. S. W. Allen for the two illustrations.

Cardiff.

\section{Clinital âtotes:}

MEDICAL, SURGICAL, OBSTETRICAL, AND THERAPEUTICAL.

\section{A CASE OF ERYTHEMA NODOSUM ET BULLOSUM}

By J. A. Gibb, M.B., C.M. ABERD.

THE following case in a male patient has recently occurred in my practice. The uncommon character of the affection may make its report of some interest to the readers of The LANCET. The patient had undergone a considerable amount of climatic exposure prior to the attack, which commenced on March 5th of this year with stiffness in the jaws and pain in the limbs. On the 7th I was called in and I found the patient in the following condition. He was in bed and was sweating profusely. The left knee was enlarged and red but was not painful, and there was ino odema. On the inner side of the right tendo Achillis were several large erythematous spots, oval in shape and of about the size of a half-crown. The same condition existed over the condyles of both humeri extending some little way down the ulnar side of the forearm. Both elbow-joints were enlarged but there was no odema. The temperature was $99^{\circ} \mathrm{F}$. and the pulse was 92 . The treatment adopted was the administration of salicylate of soda and bicarbonate of soda, and a free action of the bowels was obtained. 1 again saw the patient on the 9th. The left knee was quite normal in appearance and the spots on the right leg had all but disappeared. The whole of the left arm was very much swollen, tense, and hard from the shoulder to the finger-tips. The right arm was the same, but in addition on the inner aspect of the humerus was a bullous eruption consisting of six large red blebs each of about the size of a pigeon's egg. One of the bullæ was surrounded at its base by a number of smaller vesicles on a red base. Although there were no bullæ on the left arm the whole of the inner aspect of the humerus bad the appearance of a bruise in the first stage, the same as the right arm with the exception of the bullæ. The temperature was $101^{\circ}$. The tongue was red. The patient had been restless all night and complained that he saw a number of steamengines and various mechanical things which he knew nothing about. I ordered him a sleeping draught of the solution of hydrochlorate of morphia. On the loth the left arm was considerably improved, the redness disappearing in the ordinary stages of a bruise. The right arm was still very much swollen and there was a good deal of cedema. The temperature was normal, I now gave the patient one-grain doses of quinine and continued it for two days with no marked result. On the 12th I started giving him arsenic in five-minim doses three times a day. This was continued until April 1st, when I discontinued seeing the patient. By that time he had regained normal movement about the elbow-joints. The bullæ had ruptured and were quite healed with no scarring and very little pigmentation. On looking up the subject I find that cases of bullous erythema have been recorded by Dr. Daffin, Dr. Crocker, Dr. Frederick Taylor, and Dr. Pye-Smith. Although the bullous eruption was not symmetrical, yet the discoloration was the same in both arms, and both elbow-joints were affected at the same time and in the same way. Its combination with erythema nodosum inclines me to think that this case was one of erythema bullosum and not pemphigus. There was never any heart affection throughout the case. I examined the patient from time to time. There was no sugar or albumin in the urine. He was always a healthy man. He could only remember being ill once before and that was from typhoid fever. He was fiftysix years old and robust.

Aston-Upthorpe, Berkshire.

\section{TUMOUR OF THE KIDNEY CONTAINING EMBRYONIC MUSCLE FIBRES.}

By Bruce Buchanan Morton, M.B., C.M. Glasg.

ON account of the rarity of such cases a short clinical description and pathological report of the following case will probably be of interest.

On Nor. 24th, 1897, Dr. Johnstone, Whetley Hill, Bradford, requested me to visit a male child, aged two years, who had a large abdominal swelling, first noticed four months previously and since growing rapidly. No pain or tenderness was complained of by the little one, who took his food well but had of late months lost flesh and suffered from periods of constipation which had to be relieved by medicine. The tumour occupied the whole abdominal cavity; it bulged rather more to the left side and forwards and there were distended veins overlying it. It was smooth, hard, and moveable in a limited range towards the middle line. Percussion was absolutely dull over the whole area of the swelling, with a tympanitic note in the right side flank only. The tumour felt heavy and solid and was probably of the size of a small football. The urine was reported by Dr. Johnstone to be free from blood or albumin. With his concurrence, considering the probability of malignant conditions and the early and high mortality after removal of such tumours, no operation was advised. The child lingered till Christmas Day and seemed to die from starvation by general pressure and flattening causing chronic intestinal obstruction.

At the post-mortem examination, which was confined to the abdomen, the tumour was found to have its base in the left lumbar and hypochonariac regions; it was covered by layers of descending meso-colon, the descending colon itself being stretched and flattened over it from above downwards. The rest of the intestines lay empty, collapsed, and flattened in the right flank. The right kidney was normal in all respects, as was its suprarenal body. This on the left side was not found but may have been atrophied by the pressure of the large tumour which seemed to spring from the sinus of the kidney or the loose tissue surrounding the hilum, the pelvis of the kidney and the ureter being free from growth and only compressed, as also was the kidney proper, which lay opened out as two leaves from its anterior to its posterior border. There were no enlarged glands in the abdomen. Both testes had descended. The tumour itself weighed 6lb. $2 \mathrm{oz}$.; it had a tense, thick capsule and was spherical in shape. On section an outer white or pink rind was seen $1_{\frac{1}{2}}$ in. in thickness and like the outer fatty layer of a ham. This enclosed an inner mass of softer substance streaked with pink tracts and reddish-brown areas and with scattered hæmorrhages. Further, towards the base of the tumour, a large clot was turned out: A hard nodule was felt at the inner margin of the rind and was removed for examination. The : tumour, kidney, and ureter were removed to the museum of Bradford Infirmary. The renal vessels of the left side were in calibre much above normal or those of the 